\title{
CONSUMO E IDENTIDADE: O CABELO AFRO COMO SÍMBOLO DE RESISTÊNCIA
}

\author{
Cláudia Ferreira Alexandre Gomes ${ }^{1}$ \\ Laura Susana Duque-Arrazola ${ }^{2}$
}

\begin{abstract}
Resumo: O artigo discute a ressignificação do cabelo crespo na construção da identidade negra no contexto da sociedade de consumo. Esta sociedade de base escravocrata, como a brasileira, tem atribuído principalmente às mulheres negras, uma marca racial de inferioridade, expressada sobretudo, em seus cabelos crespos. No entanto, nos últimos anos, estes mesmos cabelos, são vistos como expressão identitária e assumidos como resistência política racial da negritude, o que também tem se expressado no surgimento de um nicho mercado voltado para a população negra: o mercado de cosméticos afro. Os dados apresentados são provenientes de entrevistas semiestruturadas realizadas entre os meses de janeiro e fevereiro de 2017 com 15 mulheres negras consumidoras de cosméticos afro. As entrevistas foram realizadas em eventos voltados para a população negra como os Toques no Terreiro de Xambá em Olinda-PE e a Terça Negra no Pátio de São Pedro em Recife-PE. Para preservar a identidade das entrevistadas, foi atribuído a cada uma, um nome feminino de origem africana. Para a análise dos dados foi utilizada a análise do discurso.
\end{abstract}

Palavras-chave: cabelo afro; consumo; cosméticos afro; identidade; negritude.

\section{CONSUMPTION AND IDENTITY: AFRO HAIR AS A SYMBOL OF RESISTANCE}

Abstract: The article discusses the re-signification of the curly hair and the construction of black identity inside our society of consumption. Like the Brazilian one, this slave-like society has attributed a racial mark of inferiority to black women that is expressed by their frizzy hair. However, in the last few years, this hair is seen as an expression of black identity and a racism reasoning of negritude, which has also been conveyed in the forthcoming of a niche commerce for the black community: the afro cosmetics' market. The data presents semi-structured interviews made between January and February 2017 with 15 black women who consume afro cosmetics. The interviews took place in events made for the black population such as the "Candomblé" manifestations on "Terreiro de Xambá" in Olinda, Pernambuco and in "Terça Negra", an event that happens every week on the "Praça de São Pedro" in Recife, Pernambuco, which is directed to black culture. Each woman was assigned a female name of African origin to preserve their identity and the interviews were assayed using the discourse analysis.

\footnotetext{
${ }^{1}$ Doutoranda em Sociologia pela Universidade Federal da Paraíba. Mestra em Consumo, Cotidiano e Desenvolvimento Social pela Universidade Federal Rural de Pernambuco. Pesquisadora do Grupo de Estudos e Pesquisas em Educação, Raça, Gênero e Sexualidades Audre Lorde (Geperges Audre Lorde) da UFRPE. Integrante do Núcleo de Estudos e Pesquisas sobre a Mulher (Nupem) da UFRPE. E-mail: claudia83gomes@gmail.com

${ }^{2}$ Coordenadora do Programa de Pós-graduação em Consumo, Cotidiano e Desenvolvimento Social da Universidade Federal Rural de Pernambuco. Líder do Núcleo de Estudos e Pesquisas sobre a Mulher (Nupem) da UFRPE. Professora do Departamento de Ciências Domésticas da UFRPE. Doutora em Serviço Social pela Universidade Federal de Pernambuco. E-mail: 1sduquearrazola@gmail.com
} 
Keywords: afro hair; consumption; afro cosmetics; identity; blackness.

\section{LA CONSOMMATION ET L'IDENTITÉ: CHEVEUX AFRO COMME SYMBOLE DE RÉSISTANCE}

Résumé: L'article aborde la resignification des cheveux afro dans la construction de l'indentité noire dans le contexte d'une société de consommation. Cette société est fondée sur l'esclavage, comme la brésilienne qui a attribué principalement aux femmes noires, une marque rationnelle d'infériorité, qui est celle cheveux afro. Cependant, au cours des dernières années, ce type de cheveux, est considéré comme l'expressions d'une identité, et supposé comme résistance politique radicale de proviennent, qui a généré une niche de marché pour la population noire: le marché des cosmétiques afro. Les données présentées ont été réalisés d'entretiens menés en janvier et février 2017 avec 15 femmes noires consommant des produits afro. Les entretiens lors d'événements pour la population noire comme le Toques no Terreiro de Xambá situé dans la ville de Olinda et Terça Negra no Pátio de São Pedro situé dans la ville de Recife. Pour préserver l'identité des personnes interrogées, un prénom féminin d'origine africaine été attribué aux interviewés. Pour l'analyse des données nous avons utilisé l'analyse de discours.

Mots-clés: cheveux afro; consommation; cosmétiques afro; identité; noirceur.

\section{CONSUMO E IDENTIDAD: EL CABELLO AFRO COMO SÍMBOLO DE RESISTÊNCIA}

Resumen: El articulo problematiza la resignificación del cabello crespo en la construcción de la identidad negra, en el contexto de la sociedad de consumo. Tal sociedad, de base esclavista, como la brasileira, ha atribuído una marca de inferioridad en especial a mujeres negras, lo cual se expressa, sobre todo, en los cabelos crespos. Sinembargo, en los últimos años estos mismos cabellos crespos, están siendo vistos y significados como expressão identitaria y assumidos como resistência política racial da negritud, esto mismo se ha expressado en el surgimento de un nicho de mercado dirigido a la poblacion negra: el mercado de cosméticos afro. Los dados que se presentan aqui provienen de la entrevistas semiestructuradas, realizadas nos meses de Enero e febrero de 2017 com 15 mujeres negras. Las entrevistas fueron realizadas en eventos dirigidos a la poblacióm negra como: Toques no Terreiro de Xambá em Olinda - Pernambuco e a Terça Negra em el Pátio de São Pedro, em Recife - Pernambuco. Para preservar la identidad de las entrevistadas, se le atribuyo a cada una um nombre feminino de origem africana. A análise de los datos se apoyó em la Análise del discurso.

Palabras-clave: cabello afro; consumo; cosméticos afro; identidad; negritud.

\section{INTRODUÇÃO}

As práticas de consumo da maioria da população negra brasileira, por muito tempo reduziam-se à compra de bens necessários para sua manutenção cotidiana. Para a grande maioria das famílias negras brasileiras, sua renda era oriunda do trabalho precariamente remunerado, a exemplo do trabalho doméstico. Vinha também do trabalho artesanal, pesqueiro, da extração mineral, do cultivo da terra ou do pagamento de um salário-mínimo, isto, no Governo de Getúlio Vargas nos anos de $1930^{3}$.

\footnotetext{
${ }^{3}$ O salário-mínimo brasileiro foi instituído pelo Presidente Getúlio Vargas em 1936, mas foi oficializado como tal em 1940, quando se fixara seus valores. Contudo, no Censo de 2010 revelou-se que metade da
} 
Passado por décadas e mais décadas, o acesso às compras pela população negra, dava-se nas feiras e mercados tradicionais, exercitando um consumo até então, restrito às necessidades básicas. Até porque, como explica Livia Barbosa (2006), consumir seja para a satisfação de necessidades básicas ou supérfluas, é uma atividade presente em toda e qualquer sociedade humana.

O nível de escolaridade da população negra tem crescido substancialmente, permitindo um aumento em sua renda, o que possibilitou sua inserção no mercado como consumidora para além das necessidades básicas. Os programas sociais de transferência de renda, têm contribuído com novas práticas de consumo de mulheres e homens negros.

Por meio do aumento do nível de escolaridade e de renda, negras e negros incorporaram-se em outras instâncias da estrutura social brasileira, significadas como lugares de status, a exemplo das universidades, o que tem levado o mercado a diversificar suas mercadorias, disponibilizando diversas linhas de produtos, especialmente nos setores de higiene pessoal e cosméticos em geral, específicos para negras e negros.

Contemporaneamente, em pleno auge da cultura e das práticas de consumo, de novos estilos de vida, os movimentos negros brasileiros, têm levado à frente o processo de afirmação da negritude para a maioria da população negra.

A narrativa dos movimentos negros, sempre se opôs ao discurso de democracia racial $^{4}$ que operava o ideal de nação. Daí deriva a complexidade do racismo brasileiro. Por meio do disfarce ou do velamento, instituiu-se o que Kabengele Munanga designa como "racismo manhoso". Não é aberto e explícito, mas implícito e silencioso (Azevedo, 2018).

A luta contra a dominação, exploração, discriminação racial, de classe e gênero tem levado ao surgimento de diferentes movimentos históricos de lutas sociais e políticas, o que na estrutura do país acabou por provocar a busca de identidade e pertencimento de ser negra/o pelos grupos que estão representando essa população.

população brasileira vivia com até $\mathrm{R}$ \$ 375,00 por mês, menos de um salário-mínimo, que nesse ano era de $\mathrm{R} \$ 510,00$, sendo que $8,5 \%$ da população vivia com uma renda de menos de R \$ 70,00 por mês, sendo 70,8\% dela, negra. <https://pt.globalvoices.org/2011/11/24/brasil-censo-populacao-negra/> (març.2017)

${ }^{4}$ (...) Erigiu-se no Brasil o conceito de democracia racial, segundo esta, pretos e brancos convivem harmoniosamente, desfrutando iguais oportunidades de existência. (...) A existência dessa pretendida igualdade racial constitui o 'maior motivo de orgulho nacional' (...)". No entanto, "devemos compreender democracia racial como significando a metáfora perfeita para designar o racismo estilo brasileiro: não tão óbvio como o racismo dos Estados Unidos e nem legalizado qual o apartheid da África do Sul, mas eficazmente institucionalizado nos níveis oficiais de governo assim como difuso no tecido social, psicológico, econômico, político e cultural da sociedade do país (Nascimento, 1978, p.41) 
No interior desse processo, tem-se dado um outro: o de resistência racial, assumido e visualizado no crescimento do uso do cabelo afro, sobretudo pelas mulheres negras. Sendo assim, o cabelo como parte de um corpo social, pode ser utilizado para melhor compreensão das relações entre mulheres e homens negros e a sociedade.

Segundo King (2015, p. 8) "os cabelos são considerados em diversas culturas como elementos marcantes da construção da beleza feminina", fornecendo informações sobre as características de cada indivíduo.

King (2015, p.8) informa ainda:

Definido por muitos como "a moldura do rosto", o cabelo pode dar informações sobre as origens, pertencimentos a grupos sociais e hábitos de uma pessoa, aproximando ou afastando indivíduos enquanto elementos de identidade corporal. Eles possuem uma grande capacidade de expressão simbólica, vinculados a um contexto sociocultural.

O entendimento da simbologia do corpo negro e dos sentidos da manipulação de suas diferentes partes, entre elas, o cabelo, pode ser um dos caminhos para a compreensão da identidade negra em nossa sociedade.

Diante do exposto, a fim de contemplar uma melhor apreensão do objeto de estudo em questão, o artigo foi estruturado em cinco tópicos. No primeiro tópico é apresentado o procedimento metodológico, no qual explicamos os caminhos percorridos ao longo da pesquisa. O segundo tópico, aborda as mudanças ocorridas no campo do consumo, especialmente no que se refere a criação de nichos de mercados voltados para a população negra, particularmente o nicho de cosméticos afro. O terceiro tópico faz uma breve contextualização sobre o surgimento da indústria, especificamente o surgimento da indústria de cosméticos afro. $\mathrm{O}$ quarto tópico faz uma reflexão a respeito do cabelo afro/crespo como elemento central na construção da identidade negra, sobretudo para as mulheres negras. O quinto e último tópico, trás algumas considerações sobre o fenômeno pesquisado, onde podemos constatar que o cabelo é um dos principais focos de preocupação para a população negra, principalmente para as mulheres negras, ele deixa de ser um simples traço fisiológico, uma vez que carrega um sentido social, enquanto signo de identidade.

\section{CAMINHO METODOLÓGICO}


O artigo desenvolvido é uma pesquisa de natureza qualitativa, isto pela particularidade que a caracteriza: uma relação dialógica com os sujeitos da mesma (Minayo, 2009).

Esta abordagem foi escolhida por permitir captar e explicar expressões de transformações, valorações, por revelar as aparências da realidade, suas particularidades e singularidades, que podem ser explicadas no bojo da realidade concreta, a sociedade de consumo.

As pessoas pesquisadas foram quinze (15) mulheres que se afirmam e reconhecem-se como negras, com idades entre 19 e 54 anos, com escolaridade entre ensino médio e superior completo, cuja renda varia entre $\mathrm{R} \$ 400,00$ e $\mathrm{R} \$ 5.000,00$ todas moradoras da Região Metropolitana de Recife (Olinda, Paulista e Recife) - Pernambuco. Estas mulheres foram encontradas em espaços sociais públicos considerados referências para a comunidade negra: o Pátio de São Pedro ${ }^{5}$ em Recife, PE e o Terreiro de Xambá ${ }^{6}$ em Olinda, PE, pretendendo assim, captar informações mais diretas sobre o cotidiano e a interação delas, observando diretamente a relação com o consumo, suas sociabilidades, as escolhas do modo de usar o cabelo, o vestir e até os artigos consumidos durante a socialização.

Para a coleta de informações, foram realizadas entrevistas semiestruturadas e também observação participante, pois a combinação dessas técnicas permite uma maior aproximação dos comportamentos sociais a partir das relações humanas, a fim de

\footnotetext{
${ }^{5}$ O Pátio de São Pedro, no bairro de Santo Antônio, testemunha a diversidade das manifestações populares tradicionais de Pernambuco. Suas ruas são palco de um comércio vivo e pulsante. O local remete ao passado, seja pelas procissões e manifestações da cultura negra, do final do século XIX, seja pelo ar boêmio, que teve seu auge nas décadas de 1970 e 1980, quando os bares Banguiê, Aroeira, Buraco do Sargento e Buraquinho reuniam poetas e intelectuais, celebrando a arte e a boa cerveja gelada. Nele acontecem durante todo o ano apresentações musicais e danças representativas dos ciclos carnavalesco, junino e natalino, da cultura negra e do movimento mangue. Além disso, o Pátio de São Pedro foi um dos lugares no Recife, que recebeu alguns monumentos que sinalizam para as/os passantes sobre a cultura negra no Recife e a história da escravidão. A esse respeito ver: Guillen, Isabel Cristina Martins. Lugares de memória da cultura negra no Recife. Inscrever a memória na cidade. XIV Encontro Nacional de História Oral. Unicamp: Campinas, 2018.

${ }^{6}$ A Tradição Xambá é uma forma de religiosidade afro-brasileira que foi trazida para o Recife no início do século XX (entre as décadas de 1910-1920). Sendo assim, sua tradição em terras pernambucanas teve que ser reinventada. A Sociedade Africana Santa Bárbara de Nação Xambá, também é conhecida como Terreiro de Xambá ou Ilê Axé Oyá Meguê. O Terreiro de Xambá se localiza na Rua Severina Paraíso da Silva, 65 no bairro de São Benedito, denominado Portão do Gelo, em Olinda - PE. Sobre isso ver: Oliveira, Jéssica Silvestre de Lira; Campos, Zuleica Dantas Pereira. Tradição e resistência no terreiro xambá: o resgate de uma herança. IV Colóquio de História: Abordagens Interdisciplinares sobre História da Sexualidade de 16 a 19 de Novembro de 2010.

Disponível em: http://www.unicap.br/coloquiodehistoria/wp-content/uploads/2013/11/4Col-p.692.pdf Acesso em 19/05/17.
} 
conseguir obter as dimensões práticas e simbólicas da sociabilidade em relação ao consumo e todas as significâncias que essa junção pode proporcionar.

Maria Izaura Pereira Queiroz (1988), ao tratar da entrevista semiestruturada, a considera uma técnica de coleta de dados que supõe uma conversação continuada entre informante e pesquisador/a e que deve ser dirigida por este/esta, de acordo com seus objetivos.

As entrevistas

As entrevistas ocorreram entre os meses de janeiro e fevereiro de 2017 e foram realizadas em eventos voltados para a população negra: Toques no Terreiro de Xambá e a Terça Negra ${ }^{7}$.

No que concerne ao método de análise, os dados e falas coletadas foram analisadas com apoio do método de Análise do Discurso, apoiando-se em Eni Orlandi (2010) a quem se referencia a chamada linha francesa de análise do discurso. Para esta escola, o discurso não é reduzido ao gramatical e linguístico, mas entendido como expressões de uma fala concreta escrita ou falada, que exprime sentidos (discurso): um dito que não é dito (Orlandi, 2010).

Segundo Eni Orlandi (2010) as falas dos sujeitos estão dotadas de certos "esquecimentos", os quais estão ligados a possíveis limitações no discurso, bem como a expressões que não poderiam ser reveladas, as quais passam a ser omitidas ou ocultadas por quem fala. A análise do discurso, depreende e apreende os sentidos dispostos no discurso das entrevistadas, considerando não apenas o dito, mas o não dito.

Nesse sentido, a constituição simbólica do consumo é produzida dialeticamente entre a interação de representações e discursos, envolvendo elementos relacionados às palavras, às imagens, às emoções e ao contexto cultural no qual essas dinâmicas estão imersas (Varman \& Belk, 2008).

\footnotetext{
${ }^{7}$ A Terça Negra é um projeto proposto pelo Movimento Negro Unificado-PE, iniciado no ano de 2000, quando o MNU-PE era coordenado por Arnaldo Vicente da Silva Filho (Nado), Mano Silva e Adeildo Leite Araujo. Arnaldo Vicente (Nado) informou que a inspiração veio da Terça da Benção, evento que aglutina milhares de pessoas no bairro do Pelourinho em Salvador todas as terças-feiras e que na década de 1980 era reduto de militantes e artistas negros (Pinho,1998). A partir disso viu-se a necessidade de criar um espaço, que trouxesse as entidades negras para a mídia, ou seja, a necessidade de criar um espaço negro no bairro de Recife. Em primeira mão, o projeto da Terça Negra foi apoiado pelos afoxés Ilê de Egba, Oxum Pandá e Ara Ode, bem como pelos blocos afro Raízes dos Quilombos e Obá Nijé. Também contribuíram: militantes, ex-militantes do MNU-PE e alguns parlamentares que ajudavam financeiramente para garantir o transporte para os grupos participarem e para o aluguel do som. A respeito disso ver: Queiroz, Martha. Para além do carnaval: O Movimento Negro na cena cultural na cidade do Recife. Anais do XXVI Simpósio Nacional de História - ANPUH • São Paulo, julho 2011. Disponível em: http://www.snh2011.anpuh.org/resources/anais/14/1313018305 ARQUIVO_MarthaRosaANPUHCOMP LETO10ago.pdf Acesso em: 19/05/17.
} 
Canclini (1996) em sua abordagem ao consumo, considera-o como muito importante para entender os/as cidadãos/as, porque a participação social também é organizada através do consumo.

\section{MUDANÇAS NO CAMPO DE CONSUMO: A POPULAÇÃO NEGRA TAMBÉM CONSOME}

De acordo com Lívio Sansone (2000), o consumo cria hierarquias não apenas de classe, mas também de cor, passando a funcionar como marcador étnico e como modo de resistir à opressão e assumir uma aparência negra.

Sansone (1998) e Barbosa (2006) consideram que uma categoria negada as/os negras/os é o status de consumidoras/es. Durante muito tempo, o consumo como fenômeno do mercado "excluiu a população negra". Devido ao acesso a um maior nível de educação, renda e consumo, negras/os passaram a ser observada/os não somente como indivíduos que sobrevivem, mas que também consomem (Soares, 2002).

Mudanças sociais estão se refletindo no mercado de consumo, que exprime um movimento de resistência racial com a inserção de uma significativa parte da população negra na cultura do consumo, em vários setores do mercado de consumo no Brasil: tanto pelo uso e significações relacionadas com a valorização da negritude, quanto pela relação beleza e poder de compra (Mizrahi, 2015).

Estudos desenvolvidos sobre o comportamento do/da consumidor/a têm apresentado a etnia e os objetos étnicos, como categorias benéficas às decisões de consumo (Soares, 2002). No entanto, no Brasil, apesar de a população negra apresentar forte influência cultural e representação demográfica, poucas pesquisas têm sido desenvolvidas no intuito de compreender como a dinâmica cultural brasileira influencia a dinâmica mercadológica do país e o comportamento das/dos consumidoras/es.

De acordo com Lívia Barbosa (2006), aproximadamente 25\% da classe média brasileira é composta por não brancos, à qual corresponde a população negra e constitui um mercado com poder de compra que movimenta $\mathrm{R} \$ 46$ bilhões ao ano, gastos com produtos específicos para essas/es consumidoras/es, denominados produtos étnicos/afro específicos às etnias negras.

Considerando que as relações de consumo também são relações sociais e que estas também são contraditórias e expressam materializações do consumo, entende-se porque o uso de alguns produtos por parte da população negra, a exemplo dos 
cosméticos afro, chama a atenção e seu consumo apresenta-se contraditório. O mesmo mercado que dificultava o acesso de negros/as, agora transforma-se em nicho de mercado para essa população, em um momento em que a negritude assume uma expressão racialmente política e identitária, existindo nela um certo circulante monetário.

Segundo Hall (2005), uma das principais expressões da globalização, é a mercantilização da etnia e da alteridade. Isso ocorre na sociedade contemporânea pela fluidez e hibridização cultural das identidades provocando fascinação na percepção das diferenças culturais. Esta dialética retoma as discussões sobre a raça/etnia, sendo refletida no mercado de consumo através de estratégias de segmentação que exploram as diferenças locais e globais.

Quanto a aceitação da identidade negra e o consumo de cosméticos afro a entrevistada Halima afirma:

Eu acho que agora a gente tá vivendo uma nova fase, onde as pessoas tão se aceitando mais né? As pessoas negras estão em busca desses produtos (cosméticos afro). Daí o mercado com toda a estratégia de vender, cria essas linhas para cabelos, pra os negros (Entrevista, Halima, 2017).

Halima lembra o momento identitário que a população negra vem passando: de um lado um processo de autoaceitação de sua identidade racial, daí a busca de cosméticos específicos para sua raça. Do outro lado o mercado, que percebe essa dinâmica identitária e aproveita para aumentar seu lucro com a venda de mercadorias específicas para a população negra.

No caso do mercado de consumo brasileiro, Gomes (2003) discute a construção dos sentidos e as ressignificações culturais dos cabelos crespos das/dos negras/os, tendo como pano de fundo as relações raciais brasileiras. De acordo com a autora, as estratégias de manipulação dos cabelos pelas mulheres negras ocorrem no sentido de reverter as representações negativas dessa população, em que os estigmas (cabelo ruim,) são transformados em salões afro em símbolos do orgulho negro.

Em sua fala, Ife, referindo-se aos cosméticos afro, revela:

Eu achei bom que fizeram isso, porque antes não tinha uma marca específica pra o tipo de cabelo da gente, a gente tinha que usar o que qualquer um usava... tinha cabelo liso, cabelo tingido... e tudo cabelo fino. Agora que inventaram isso pra o cabelo afro, achei legal (risos), eu mesma faço uso, meu cabelo tá bem mais definido (Entrevista, Ife, 2017). 
Ife associa a descoberta da beleza dos cabelos crespos e cacheados, à força que os produtos específicos trazem, contribuindo com a valorização da beleza dos cabelos crespos e cacheados.

Tendo em vista que os movimentos negros unificados fortaleceram sua representatividade na mídia e na construção de políticas afirmativas específicas às suas necessidades, acabaram influenciando a mudança na postura de negligenciar os/as negros/as nas estruturas mais representativas do Brasil, a exemplo das universidades, da própria mídia e das profissões historicamente de status como o direito, a medicina e engenharias. Essa mudança de postura cultural, se refletiu no mercado de consumo, tendo como resultado negras/os como foco de muitos setores de consumo no país, em especial de higiene e beleza.

Quanto a isso Dara é bem representativa:

$\mathrm{Eu}$ acho legal produtos para a beleza afro, porque a gente nem era visto no mercado e agora tá tendo um boom. Mas ao mesmo tempo eu acho que a gente tem que ser visto não só no lado da cosmética, mas nos outros lados também (Entrevista, Dara, 2017).

O sentido da fala de Dara aponta a contradição na relação mercadoria-negritudeconsumo e o mercado de cosméticos afro. Chamando a atenção para essa nova efervescência do lucro do mercado com a venda de cosméticos afro, nicho que tem crescido, embora antes o mercado atuasse como se a população negra não existisse, pois "não consumia". Dara lembra ainda, que a atenção à população negra não deve ficar só na área de cosméticos, porque garante um consumo que beneficia a indústria e o comércio, devendo se estender a outras dimensões do sujeito mulher-homem negra/o, a exemplo das áreas de educação, trabalho, saúde e moradia.

Percebe-se nas falas apresentadas, que os grupos sociais subalternizados, como a população negra, ao conquistarem novos posicionamentos sociais influenciam a demanda de produtos e serviços no mercado consumo, pois seus hábitos, gostos, valores e estilos de vida, também passam a ter influência na cultura do consumo com um número maior de consumidoras/es negras/os, fazendo com que a indústria de cosméticos passe a desenvolver e a ofertar produtos específicos para a população negra. 
A indústria de cosméticos surgiu no início do século $\mathrm{XX}$ em função da necessidade, sobretudo das mulheres, de produtos para os cuidados com o corpo, que os modos de vida urbanos exigiam, pois assim como os homens, muitas mulheres já trabalhavam fora de casa.

A importância designada à aparência do corpo, do rosto e dos cabelos (especialmente os femininos) são alguns dos inúmeros reflexos produzidos pela indústria da beleza. Tais comportamentos têm sido refletidos com o aumento de consumidoras/es de cosméticos, sobretudo nas últimas décadas, em que mulheres e homens têm influenciado no crescimento da indústria de higiene pessoal, perfumaria e cosméticos.

A indústria de cosméticos constitui um dos segmentos mais importantes da economia mundial. Em produção, o Brasil chega ao $3^{\circ}$ lugar no ranking mundial e ao $1^{\circ}$ na América Latina. A Associação Brasileira da Indústria de Higiene Pessoal, Perfumaria e Cosméticos apresentou um crescimento de $\mathrm{R}$ \$ 4,9 bilhões em 1996 para $\mathrm{R}$ \$ 43,2 bilhões em 2014 (Abihpec, 2014).

Entre os fatores que contribuem para o aquecimento do setor de cosméticos no país podem ser citados: o crescimento da participação da mulher no mercado de trabalho; o aumento do poder de consumo das mulheres, a utilização de tecnologias de ponta produzindo ganhos de produtividade e toda a valorização da estética praticada pela mídia, o que se reflete na sociedade contemporânea numa busca pela beleza, saúde e juventude (Abihpec, 2014).

No interior do processo de resistência e identidade racial, nota-se o crescimento do uso do cabelo e cosméticos afro. O mercado percebeu a demanda por cosméticos afro, impulsionada pelos valores da negritude brasileira e também por referências que surgiam na mídia.

Diante desse cenário, diferentes opções de cosméticos são desenvolvidas para atender esse crescente mercado consumidor e as estratégias dessa indústria são cada vez mais sedutoras, sendo frequentemente lançados novos produtos, ampliando e gerando novos nichos de mercado (caso dos cosméticos afro).

Quanto a isso Ona argumenta: 
Eu acho legal que foi disponibilizada mais linhas, mais coisas pra gente usar. Não só existe aquela de cachos definidos, agora existe o crespo divino. Então existe desde o cacho até o crespo, que também era uma coisa que ninguém queria dizer: ah meu cabelo é crespo (Entrevista, Ona, 2017).

Em seu discurso Ona afirma a importância dos produtos específicos e da valorização da diferença dos tipos de cabelos afro. Para ela, os produtos disponíveis devem ser não só para cabelos cacheados, mas também para cabelos crespos, pois impulsionam a população negra de cabelos crespos a realçar sua beleza negra, o que ajuda no processo de aceitação de sua identidade racial.

Consoante a isso, Farisa diz:

Eu particularmente pra usar um negócio no meu cabelo, eu sou muito assim... $\mathrm{Eu}$ vejo uma procura né, uma procura muito grande. O pessoal tem uma referência. Dizem: ó usa esse creme... a gente que é negro vai por indicação. Então essa coisa do cosmético é ótimo, porque a gente usa como referência. A gente que eu falo é a mulher negra... eu vejo uma procura né, uma procura muito grande. Eu tenho amigas que usam, que me indicam (Entrevista, Farisa, 2017).

A fala de Farisa revela perceber como positivo o aumento da procura por produtos específicos para a população negra, pois significa para ela que negras/os estão assumindo sua identidade. Mais ainda, o sentido da fala revela que assumir a negritude e os cabelos crespos e cacheados está permitindo uma troca, um partilhar que termina afirmando a identidade e assumindo os cabelos antes rejeitados.

Nesse movimento, uma dialética começa a revelar-se: um reconhecimento identitário e de resistência político racial, no bojo de um processo de mercantilização da resistência da raça e no uso e exposição pública da beleza dos cabelos afro, ressaltado e incorporado por uma cultura de consumo que se expande com o nicho dos cosméticos afro, sobretudo para as mulheres.

A respeito disso a entrevistada Bashira diz:

O empoderamento da mulher, leva elas a assumirem cada vez mais os seus cabelos. Antigamente, aqui mesmo no salão, as pessoas vinham muito alisar o cabelo, um cabelo transformado, liso, não permanentado, mas saía completamente de sua característica e hoje esse percentual caiu significativamente. Hoje a gente tem pessoas que vêm transformar, mas só pra manter sua característica e mudar só a questão da espiral do cacho, mantendo a mesma característica" (Entrevista, Bashira, 2017).

Em seu discurso, Bashira revela perceber a aceitação e valorização da identidade negra, na medida em que atualmente as mulheres negras estão assumindo sua beleza e 
identidade negra. Pode-se pensar que se deva à articulação do movimento negro unificado e à presença de mulheres negras nos espaços historicamente privilegiados como a mídia, fazendo com que mais mulheres queiram assumir sua beleza negra, principalmente no que diz respeito ao cabelo, elemento de identificação e de posicionamento sócio racial.

$\mathrm{Na}$ sociedade de consumo, beleza e identidade se confundem, visto que o mercado mercantiliza identidades criando novos nichos de mercado, como é o caso da beleza negra e seus cosméticos afro. Devido ao aumento da renda, consequência de uma maior escolarização (muitas vezes por conta de políticas de ações afirmativas) negras/os têm aumentado seu poder de consumo. Na lógica do capital e seus lucros, o mercado disponibiliza diversas linhas para atender às diferenças das/dos consumidoras/es negras/os.

A partir de sua ascensão social, negras/os têm adquirido reconhecimento por um setor da sociedade, na medida em que passaram a frequentar espaços historicamente privilegiados, como as universidades e espaços de compra como os shoppings, o que trouxe a vivência de novas sociabilidades (habitus, gostos, estilos de vida).

Sansone (2000) defende que o consumo também é um marcador étnico, bem como uma forma de oposição à opressão, uma maneira de negras/os visibilizarem mudanças em suas condições de vida ao mostrarem-se em diferentes esferas públicas, entre elas as frequentadas por brancas/os fazendo-se ver ou mesmo sendo ouvidas/os.

Como disse Mizrahi (2015), as mulheres negras com sua marca identitária (cabelos crespos, cacheados) dão outra significação ao uso dos cabelos crespos e cacheados e seu modo de expô-los com seus penteados.

Segundo o sentido do discurso de Ona:

A mulher negra é aquela coisa diferente, é um cabelo mais afro, um cabelo mais cacheado, é um jeito de olhar mais diferente, é diferente, então pra mim o que faz diferença é mais bonito (Entrevista, Ona, 2017).

Nesse sentido, para Ona, a base da beleza negra está na diversidade em que ela se manifesta e resiste, esse algo diferente em relação à beleza branca (homogênea, monótona) que mesmo hegemônica não seria tão bela. Olhar o cabelo afro, crespo, cacheado, é um ponto importante da beleza matizada, diferenciada.

Já Kinah considera que: 
A mulher negra chama mais atenção né? o charme da cor... é o destaque (Entrevista, Kinah, 2017).

Kinah atribui beleza ao diferente, ao que categoriza e significa como charme, destaque, entre eles a cor da pele, que é para ela, uma beleza mais intensa nas mulheres negras, em relação às mulheres brancas. Sua fala remete às atribuições e caracterizações da mídia hegemônica: a beleza negra é uma beleza exótica.

Segundo Mizrahi (2015 p. 32), emerge nesse charme e no exótico "um elemento potencialmente facilitador da circulação pela cidade" de homens e mulheres negros/as. Além disso, considera-se que desse modo, as mulheres negras marcam e ressignificam a negritude e a beleza dos cabelos da raça negra.

Segundo Canclini (1996), historicamente o consumo tem ganhado uma forma de expressão de cidadania, pois ao assumirem no processo de consumo, posturas e decisões, relacionadas à negritude, mulheres e homens negros afirmam pertencimentos raciais e culturais, ocupam espaços, pressionam o Estado por políticas raciais, conquistam igualdade e liberdade, adquirindo cada vez mais importância na determinação do status entre a população negra.

Analisando esse contexto social e as formas de consumo que se estabelecem no cenário mercadológico de nosso país, as empresas/marcas estão buscando formas de atingir de maneira estratégica, esse potencial público consumidor de mercadorias relacionadas à beleza negra. Conforme afirma Almeida (2011), historicamente não há maiores registros no país, que no passado existisse um mercado étnico/racial segmentado para a população negra. Percebemos hoje, que o étnico virou moda, marca estilos de vida e está cada vez mais comum no Brasil, tendo recebido grande aceitação do público negro, começando uma nova fase na cultura do consumo, que envolve os cosméticos afro, no qual a visibilidade de negras/os passa a ganhar novos contornos.

Sobre o desenvolvimento pelo mercado, de produtos específicos para a população negra, algumas entrevistadas manifestaram:

"Acho uma manobra do mercado, nada mais que isso. Eles perceberam que a população negra tá se aceitando mais, assumindo seus cabelos afro, com poder aquisitivo um pouco maior... porque antes a gente não tinha tanto. Então eles viram isso como um meio de vender mais, não é que eles valorizem o negro não, só foi isso, pra eles lucrarem cada vez mais (Entrevista Ife, 2017). 
Para Ife o mercado está produzindo e vendendo produtos específicos para a população negra, visando aumentar o lucro, haja vista que o mercado percebeu que a população negra tem hoje um poder aquisitivo maior e está aceitando sua negritude.

Assim... do mesmo modo que a gente tá tendo essa visibilidade pelo mercado de cosméticos, tanto para pele como para o cabelo, ao mesmo tempo eu acho que o foco... que a gente vive num sistema capitalista, é o lucro né, o mercado (risos) - (Entrevista, Dara, 2017).

Dara atenta para o fato de vivermos em um sistema capitalista, onde a gênese desse sistema é a acumulação do lucro, logo a visibilidade de negros/as pelo mercado de consumo seria muito mais com o objetivo de aumentar as vendas, do que valorizar a identidade negra.

Diferentemente Mali explicita:

$\mathrm{Eu}$ acho que é um pouco os dois. Eu acho que tem uma mistura de atender o mercado que ta aí, então eles vão fazer de tudo pra ganhar, pra conquistar esse mercado, porque é um mercado grande (Entrevista, Mali, 2017).

Mali entende que o mercado de cosméticos afro, ao mesmo tempo que mostra a existência da população negra, ele lucra com as vendas dos inúmeros produtos específicos para essa população. Haja vista que com a população negra, o mercado tem um grande nicho pra lucrar.

As linhas étnicas têm ganhado cada vez mais espaço no mercado, nos últimos anos, priorizando fundamentalmente a produção de produtos de beleza em geral, nos quais, produtos voltados para o cabelo afro ganham maior destaque, pois "ele é tido como o símbolo que demarca o lugar na escala social, mas também é um marcador de diferença e de autoafirmação, além de ser muitas vezes uma mensagem e um ato de resistência cultural"' (Almeida, 2011, p.5).

A criação de uma linha de cosméticos com o objetivo de enaltecer a autoestima e como projeto de reafirmação da identidade étnica por parte de segmentos negros, é uma reação ao que aconteceu no mundo da moda dos anos 1980: a apropriação de uma simbologia calcada em uma certa ideia de etnicidade e direcionada para o consumo (Santos, 2000).

O discurso de uma beleza negra mostrado pela cosmética, implica dizer que foi criado um polo irradiador de novas "habilidades culturais" em que a tonalidade, a cor e 
as diferenças de pele, problematizam, mesmo que implicitamente, o lugar do negro na sociedade brasileira (Sansone, 1991, p.131).

Ao pensar no uso de cosméticos afro é preciso refletir sobre a lógica do mercado em relação aos gostos e estilos de vida, pois o mercado transmite a falsa ideia de que cada indivíduo é autônomo, livre para escolher seu estilo e comprar o que deseja. Dentro dessa lógica, encontram-se milhares de mulheres negras dispostas a consumir "livremente" produtos que enalteçam sua beleza e identidade negra, principalmente no que diz respeito ao marcador maior de identidade: o cabelo.

\section{CABELO COMO MARCADOR DE IDENTIDADE}

Ao falarmos sobre corpo e cabelo, inevitavelmente nos aproximamos da discussão sobre identidade negra. Esta é vista como um processo que não se dá apenas no olhar do próprio negro sobre si mesmo e seu corpo, mas também na relação com o olhar da/do outra/o. Nessa relação um ícone identitário sobressai: o cabelo afro, presente em mulheres e homens negros.

Os discursos sobre a importância do cabelo na composição da estética negra, são temas de imagens aproximativas, contrativas e de conteúdo político, em que os cabelos considerados bonitos são geralmente os lisos e compridos.

Em razão da colonização cultural, negras/os usavam ferro quente (que as/os baianas/os denominam cabelo frito), pastas, alisantes e outras químicas, construindo-se um ideal negro associado ao uso desses produtos. A partir dos anos 1970, uma imagem de contraste revela um discurso político, relacionado aos reflexos do movimento cultural e comportamental do movimento negro norte-americano dos anos 1960.

A imagem do cabelo natural de negras/os, passou a ser referenciada como aquela que se contrapõe ao cabelo liso e que estaria em consonância com uma nova mentalidade do ser negro: a negritude.

A respeito disso Ife revela:

Eu observo nas ruas por aí, você via todo mundo com aquele cabelo com chapinha, escova e hoje não. Hoje é comum você vê as meninas com aquele black, se aceitando, não têm vergonha do cabelo, bota um acessório, uma flor, uma faixa... Todo mundo tá se aceitando mais hoje em dia né (Entrevista, Ife, 2017).

Ife relata o processo de aceitação da população negra em relação as suas marcas raciais, comparando o momento anterior - a negação do cabelo crespo e cacheado - por 
meio do alisamento pela chapinha e o momento atual, pois antes, as mulheres negras viviam no ideal do embranquecimento e de beleza imposto pela mídia e pelas outras esferas de poder.

Nos dias de hoje, muitas mulheres negras fazem questão de assumir sua identidade racial, principalmente por meio do cabelo, que se torna não só um elemento de beleza, mas um elemento político da negritude, destacando o uso do black power, afirmando também seu lugar na sociedade.

Como observa Cunha (1991, p.146):

A naturalidade, por sua vez, não significa a ausência total de interferência, mas ela é de outra natureza. Nela, a produção estética visa auxiliar e fortalecer os cabelos; o sentido é anterior à naturalidade, pois não vem como interferência externa, ao contrário, a precede.

O cabelo crespo, antes objeto de constante insatisfação, principalmente nas mulheres negras, agora é visto no sentido de uma revalorização da beleza negra, o que não deixa de apresentar contradições e tensões próprias do processo identitário. Essa revalorização extrapola o indivíduo e atinge o grupo étnico/racial a que se pertence. Ao atingi-lo, acaba remetendo à uma ancestralidade africana recriada no Brasil.

A respeito disso Gomes (2002, p.2) nos diz que:

O cabelo e o corpo são pensados pela cultura. Nesse sentido, o cabelo crespo e o corpo negro podem ser considerados expressões e suportes simbólicos da identidade negra no Brasil. Juntos, eles possibilitam a construção social, cultural, política e ideológica de uma expressão criada no seio da comunidade negra: a beleza negra. Por isso não podem ser considerados simplesmente como dados biológicos.

Considerando a construção histórica do racismo brasileiro, no caso das/dos negras/os, a este segmento étnico/racial, foi relegado estar no polo daqueles que sofrem o processo de dominação política, econômica e cultural e a brancas/os estar no polo dominante. O que não significa que essa separação seja aceita passivamente pela população negra.

É notável o papel desempenhado pelos cabelos, assim como a cor da pele, na construção da identidade negra, fato que determina de maneira marcante como as/os negras/os se vêm e como são vistas/os pela sociedade. Porém, dependendo do contexto social em que a/o negra/o esteja inserida/o, os cabelos continuam sendo vistos como marca de inferioridade.

Os estudos referentes ao cabelo crespo despontam no cenário historiográfico de forma bastante tímida e lenta à medida que [...] Antes de 2002, o tema aparece em 
alguns trabalhos, como o de Sodré (1999), e o de Santos (2000) discutindo como é elaborada a imagem negra positiva, em oposição as representações negativas dominantes.

Em sua análise sobre o corpo, Nilma Lino Gomes (2003, p.8) nos diz:

O corpo é uma linguagem e a cultura escolheu algumas de suas partes como principais veículos de comunicação. O cabelo é uma delas[...] É um dos elementos mais visíveis e destacados do rosto. Em todo e qualquer grupo étnico ele é tratado e manipulado, todavia a sua simbologia difere de cultura para cultura. Esse caráter universal e particular do cabelo atesta a sua importância como símbolo identitário.

Sendo um elemento visível do corpo, o cabelo comumente apresenta-se como alvo de preconceitos, olhares e discursos racistas, assim como de inúmeras preocupações com relação ao cuidado dispensado a ele e as formas de manipulá-lo cotidianamente.

A respeito desse assunto a fala de Hanna é significativa:

$\mathrm{Eu}$ antes, quando realmente não tinha assumido o meu cabelo, eu ficava com vergonha, porque eu achava que meu cacho ele só tinha que ser baixinho, tá entendendo? Aquela coisa pra baixo assim... quando ele ficava mais alto, eu pensava, não pode. Aí depois que eu fui vendo as meninas tratando mais seus cabelos... os cabelos afro né, aí eu fui vendo que ele podia ser assim do jeito que ele é, pra cima, meio assanhado, o vento batia e eu não tava nem aí... eu acho que os cosméticos também ajudam (Entrevista, Hanna, 2017).

Hanna acredita que o uso do cosmético afro, a ajudou no processo de aceitação de seus cabelos como identidade racial, pois antes ela tentava fazer com que seu cabelo se aproximasse ao máximo do padrão branco, ou seja, um cabelo liso, sem volume e que não ficasse assanhado. Com o uso do cosmético afro, aliado a outras referências que ela via na rua, percebeu que seu cabelo poderia ser bonito, charmoso do jeito que é: com volume e meio assanhado.

Na realidade, o cabelo é um dos principais focos de preocupação estética entre as mulheres negras, ele deixa de ser um simples traço fisiológico uma vez que carrega um sentido social, o que nos faz perceber que enquanto signo de identidade, o mesmo encontra-se inserido na cultura de um dado espaço territorial ou de uma dada comunidade, o jeito como ele é usado, se solto, se preso, se cacheado, se alisado, se coloridos, etc., diz muito de como ele é visto e o que significa a cada grupo social (Carneiro, 2005).

A respeito disso Dayo revela: 
Agora principalmente as mulheres negras têm como cuidar de seu cabelo, de sua pele com produtos que foram feitos pensados para a gente, como são específicos o resultado é bem melhor (Entrevista, Dayo, 2017).

Em suas falas Hanna e Dayo revelam que o consumo de cosméticos específicos para a população negra, ajuda no processo de aceitação da própria identidade negra, pois esses cosméticos auxiliam no cuidado da beleza dos cabelos crespos e cacheados, no cuidado da pele negra, que merecem cuidados específicos, pois antes precisavam fazer uso de produtos que eram voltados para a população branca.

De a cordo com Gomes (2002), nos diversos espaços sociais (escola, trabalho, lazer) ocorrem situações preconceituosas e por isso há uma classificação das pessoas segundo o padrão estético, principalmente no que diz respeito a nomes pejorativos dirigidos ao cabelo da raça negra. Alguns se referem aos cabelos crespos/afros como "cabelo de bombril", "fuá", "pixaim”, “cabelo duro", "cabelo de picumã"... Apelidos dados ao cabelo das/dos negras/os, visto como símbolo de inferioridade, sempre associado à artificialidade (esponja de bombril) ou com elementos da natureza (ninho de passarinho, teia de aranha enegrecida pela fuligem), (Gomes, 2002, p. 45).

Continuando sua linha de pensamento Gomes (2006, p.168) revela:

O processo identitário do negro tem como componente principal a violência racista, que vai da cor ao corpo negro. Há uma complexidade envolvendo o processo de "tornar-se negro" na sociedade brasileira. A violência é a pedra de toque, o núcleo central do processo identificatório dos negros. Ser negro é ser violentado de forma constante, contínua e cruel, sem pausa ou repouso, por uma dupla injunção: a de encarnar o corpo e os ideais de ego do sujeito branco e de recusar, negar, anular a presença do corpo negro.

De acordo com Gomes (2002), grande parte das mulheres negras que adota os diversos tipos de alisamentos, é por ter sofrido em sua infância e adolescência algum tipo de preconceito, devido às dificuldades enfrentadas por elas no manuseio dos cabelos, por serem crespos.

Basta lembrar a forma violenta e cruel imposta aos escravos através da raspagem dos cabelos, ato que os definia como inferiores perante à classe branca, deixando-os com o sentimento de mutilação, pois para estes, o cabelo era associado à sua identidade e dignidade.

A respeito disso Gomes (2002) nos diz:

O cabelo tem sido um dos principais símbolos utilizados nesse processo, pois desde a escravidão tem sido usado como um dos elementos definidores do lugar do sujeito dentro do sistema de classificação racial brasileiro. 
Consoante a isso Halima revela:

Hoje pra mim, minha pele e meu cabelo representam quem eu sou... quem eu sou pra mim e depois de mim pra o outro também, quem eu vou mostrar ser, porque antes eu tinha pele de negra, cabelo de negra e queria viver como branca e mostrar para a sociedade que eu era branca. De jeito nenhum eu marcava no senso da escola que eu era negra, preta... não! Aí todo mundo ficava mangando né? Hoje não, hoje eu sou negra, me afirmo como negra e gosto do meu cabelo e da minha pele como negra (Entrevista, Halima, 2017).

Halima expõe a alienação que vivia envolvida em relação à sua identidade negra, pois antes de aceitar-se fazia de tudo para embranquecer-se. Muitas negras e negros tentam se embranquecer por perceberem que em nossa sociedade, mulheres brancas e homens brancos costumam ter privilégios só pelo fato de serem brancas/os e sabendo que são as mulheres negras, os homens negros e as/os indígenas que estão na base da pirâmide social, principalmente as mulheres negras, tentam aproximar sua imagem, da imagem branca.

Os marcadores sociais de desigualdade, gênero, raça, classe, sexualidade, promovem opressões, discriminações, exclusões e violências, e são acionados pelas mulheres negras para mobilizar situações de agenciamento e empoderamento no questionamento das estruturas de opressão (Cardoso, 2018, p.320).

Ife relata:

Eu acho a mulher negra linda e eu gosto quando eu olho no espelho, eu vejo meu cabelo, minha pele... (Entrevista, Ife, 2017).

Ife relaciona a representação de sua pele e seu cabelo à beleza, afirmando que gosta do resultado do que vê ao olhar-se no espelho. Fato muito diferente de antigamente, ao qual a grande maioria das mulheres negras tentava esconder ao máximo sua beleza natural e viviam tentando aproximar-se do ideal de beleza branca, sendo isso fruto do racismo sofrido ao longo dos anos.

Os estigmas negativos que recaem sobre o cabelo crespo são frutos do processo de europeização no período colonial brasileiro, que legitimava o modelo ideal de beleza como sendo o da mulher/homem branca/o, colocando negras/os e indígenas, e seus corpos, em um sistema de dominação que oprimia sua estética, tida como feia, fora dos padrões.

\section{CONSIDERAÇÕES FINAIS}


O cabelo é um dos principais elementos de afirmação identitária da população negra e é também, o símbolo representativo do desafio enfrentado por negras e negros em uma sociedade em que ainda prevalecem os padrões de beleza europeus.

O cabelo como parte de um corpo social, pode ser utilizado para uma melhor compreensão das relações entre negras e negros e a sociedade, pois é considerado em diversas culturas como elemento marcante da construção da beleza, principalmente a feminina, fornecendo informações sobre as características de cada indivíduo.

A manipulação do cabelo de negras e negros pode ser vista como a continuidade de elementos culturais africanos, ressignificados no Brasil. Descobrir a africanidade, a negritude presente na manipulação do cabelo de negras/os na atualidade da sociedade de consumo, em que este traz desdobramentos nas identidades, pertencimentos e distinções sociais, constitui uma das preocupações primordiais para a definição da força histórica e cultural desse segmento étnico/racial.

O fato de usar um cosmético específico para seu grupo racial, leva a crer que negras e negros buscam não só uma mudança estética, pois junto a isso, existe a tentativa de recuperação de sua autoestima, além da construção e reafirmação de sua identidade negra, frente a uma sociedade que ainda subjuga negras e negros.

\section{REFERÊNCIAS}

ABIHPEC [Associação Brasileira das Indústrias de Higiene Pessoal e Cosméticos]. Revolução nas prateleiras. Disponível em: https://abihpec.org.br/publicacao/anuario-abihpec-2014. Acessado em: 14 de julho de 2016.

ALMEIDA, Alex S. M. Identidade e consumo: o que compreender sobre o consumo da chamada "linha étnica" e a relação com identidade na classe média negra. In: XXVI Simpósio Nacional de História - ANPUH, São Paulo, 2011.

AZEVEDO, Amailton Magno. Da Crítica ao racismo à emancipação da cultura negra. Revista da $A B P N$, v.10, n. 26, 2018, p. 276-290.

BARBOSA, Lívia; CAMPBELL, Colin (Org.). Cultura, consumo e identidade. Rio de Janeiro: Ed. FGV, 2006.

CANCLINI, Nestor Garcia. Consumidores e cidadãos. Rio de Janeiro: UFRJ, 1996.

CARDOSO, Cláudia Pons. Experiências de mulheres negras e o feminismo negro no Brasil. Revista da ABPN, v. 10, n. 25, 2018, p. 317-328.

CUNHA, Olívia G. Corações rastafari: lazer, política e religião em Salvador. Dissertação (Mestrado em Antropologia Social), Universidade Federal do Rio de Janeiro, Rio de Janeiro, RJ, 1991. 
GOMES, Nilma Lino. Educação, identidade negra e formação de professores/as: um olhar sobre o corpo negro e o cabelo crespo. Educação e Pesquisa, São Paulo, v.29, n.1, 2003, p. 167-182.

GOMES, Nilma L. Corpo e cabelo como ícones de construção da beleza e da identidade negra nos salões étnicos de Belo Horizonte. Tese (Doutorado em Antropologia). Universidade de São Paulo, São Paulo, SP, 2002.

GUILLEN, Isabel Cristina Martins. Lugares de memória da cultura negra no Recife. Inscrever a memória na cidade. XIV Encontro Nacional de História Oral. Unicamp: Campinas, 2018.

HALL, Stuart. A identidade cultural na pós modernidade. 10ª ed. Rio de Janeiro: DB\&A, 2005.

KING, Ananda Melo. Os cabelos como fruto do que brota de nossas cabeças. Geledés Instituto da Mulher Negra. Disponível em: https://www.geledes.org.br/os-cabelos-como-fruto-do-quebrota-de-nossas-cabecas/ Acessado em: 3 de maio de 2017.

MINAYO, M. Cecília de Souza (org). Pesquisa Social: teoria, método e criatividade. $28^{a}$ Ed. Petropolis: Vozes, 2009.

MIZRAHI, Mylene. Cabelos, Ambiguidades: beleza, poder de compra e "raça" no Brasil urbano. Revista Brasileira de Ciências Sociais, v. 30, n.89, 2015, p. 31-47.

NASCIMENTO, Abdias do. O Genocídio do Negro Brasileiro: processo de um racismo mascarado. Rio de Janeiro: Paz e Terra, 1978.

OLIVEIRA, Jéssica; CAMPOS, Zuleica. Tradição e resistência no terreiro xambá: o resgate de uma herança. IV Colóquio de História: Abordagens Interdisciplinares sobre História da Sexualidade de 16 a 19 de Novembro de 2010. Disponível em: http://www.unicap.br/coloquiodehistoria/wp-content/uploads/2013/11/4Col-p.692.pdf. Acessado em 19 de maio de 2017.

ORLANDI, Eni. Análise de Discurso: princípios e procedimentos. Campinas: Pontes, 2010.

QUEIROZ, Martha. Para além do carnaval: O Movimento Negro na cena cultural na cidade do Recife. Anais do XXVI Simpósio Nacional de História - ANPUH • São Paulo, julho 2011. Disponível em: http://www.snh2011.anpuh.org/resources/anais/14/1313018305_ARQUIVO_MarthaRosaANPU HCOMPLETO10ago.pdf. Acessado em: 19 de maio de 2017.

QUEIROZ, Martha. Relatos orais: do "indizível" ao "dizível". In: VON SIMSON, O. M. (org. e intr.). Experimentos com histórias de vida (Itália-Brasil). São Paulo: Vértice, Editora Revista dos Tribunais, Enciclopédia Aberta de Ciências Sociais, v.5, 1988. p. 68-80.

SANSONE, Livio. Os objetos da identidade negra: consumo, mercantilização, globalização e a criação de culturas negras no Brasil. Disponível em: http://www.scielo.br/scielo.php?pid=S0104-93132000000100004\&script=sci_abstract\&tlng=pt. Acessado em: 28 de setembro de 2017.

SANSONE, Livio. Racismo sem etnicidade: políticas públicas e discriminação racial em perspectiva comparada. Maná, v. 41, n. 4, 1998. p.751-783.

SANSONE, Livio. A produção de uma cultura. Estudos Afroasiáticos, v.25, n. 20, 1991. p. 12134. 
SANTOS, Jocélio T. O negro no espelho: imagens e discursos nos salões de beleza étnicos. Estudos Afro-Asiáticos, n.38, [online]. 2000, p. 49-65.

SOARES, Janaína M. A singularidade invisivel: um estudo do comportamento de consumo dos profissionais liberais negros. Dissertação (Mestrado em Ciências). Coppead/UFRJ, Rio de Janeiro, RJ, 2002. 